\title{
Article \\ Analysis of Aspect Ratio in a Miniature Rectangle Channel for Low Frictional Resistance
}

\author{
Takashi Fukuda *(D) and Makoto Ryo Harada
}

Citation: Fukuda, T.; Harada, M.R. Analysis of Aspect Ratio in a Miniature Rectangle Channel for Low Frictional Resistance. Micromachines 2021, 12, 1580. https://doi.org/ $10.3390 / \mathrm{mi} 12121580$

Academic Editor: Stéphane Colin

Received: 8 October 2021

Accepted: 16 December 2021

Published: 18 December 2021

Publisher's Note: MDPI stays neutral with regard to jurisdictional claims in published maps and institutional affiliations.

Copyright: (c) 2021 by the authors. Licensee MDPI, Basel, Switzerland. This article is an open access article distributed under the terms and conditions of the Creative Commons Attribution (CC BY) license (https:/ / creativecommons.org/licenses/by/ $4.0 /)$.
Department of Materials and Chemistry, National Institute of Advanced Industrial Science and Technology, 4-2-1, Nigatake, Miyagino-ku, Sendai 983-8551, Japan; harada2501@gmail.com

* Correspondence: fukuda-takashi@aist.go.jp

\begin{abstract}
We conducted a theoretical investigation of the cross-sectional aspect ratio of a rectangular channel to have sufficiently low frictional resistance under less than 150 of the Reynolds number. From the theoretical consideration, it was clarified that 3.40 or more is recommended as a criterion for determining the aspect ratio. This addresses the problem of determining the interval of rectangle channels, installed in a plate reactor. There is a concern that the real system does not follow the analytical solution, assuming laminar flow, since the higher aspect ratio leads to disturbances of the flow such as the emergence of vortices. However, in the channel's volume range of $(W \times H \times L)=(7.0 \mathrm{~mm} \times 0.38 \mathrm{~mm} \times 0.26 \mathrm{~m})$, such a turbulence was not observed in the detailed numerical calculation by CFD, where both calculation results were in agreement to within $3 \%$ accuracy. Moreover, even in an experimental system with a surface roughness of ca. $7 \%$, friction resistance took agreement within an accuracy of $\pm 30 \%$.
\end{abstract}

Keywords: pressure drop; friction factor; plate reactor; rectangular channel

\section{Introduction}

Microreactors have received attention because of their characteristics of rapid heat and mass transfer [1,2] which are aiming to overcome their rate-determining step [3-6]. Recently, milli-tubing or catalyst-packed columns have been applied to compact flow synthesis processes for functional chemicals (e.g., pharmaceuticals) [7-9]. A common strategy for high-throughput microchemical processes is to increase the throughput per reactor and/or to increase the number of reactors [10-12]. Plate reactors are one of the solutions for high-throughput processes, and catalytic wall-plate reactors are mainly employed in gasphase reaction systems such as Fischer-Tropsch synthesis, hydrogen production, syngas production, and methanation [13-15]. Our research group has also focused on plate reactors and has been working on the development of improved and newly structured reactors to improve catalyst loading [16-18]. Moreover, plate reactors are expected to have attractive extended functionality; installing membranes for reaction separation, micro pins or infilling packing fins for enhancing advective transport phenomena, and so on [4,5,11,17-21].

However, channel clogging is one of the problems in microreactors, which causes the shutdown of operations. A catalytic wall reactor is one of the solutions for the problem, by installing an empty space in the gap of the catalyst layers.

In catalytic wall reactors, reactants' contact with catalytic surfaces occurs by molecular diffusion rather than by advective mass transport. We have been studying methane reforming $\left(\mathrm{CH}_{4}+\mathrm{H}_{2} \mathrm{O} \rightleftarrows \mathrm{CO}+3 \mathrm{H}_{2} \Delta \mathrm{H}_{298 \mathrm{~K}}=+206 \mathrm{~kJ} / \mathrm{mol}, \mathrm{CH}_{4}+\mathrm{CO}_{2} \rightleftarrows 2 \mathrm{CO}+2 \mathrm{H}_{2}\right.$ $\Delta H_{298 \mathrm{~K}}=+247 \mathrm{~kJ} / \mathrm{mol}$ ), e.g., a gaseous large endothermic reaction, using a plate-type reactor (one type of catalytic wall microreactor) for avoiding clogging due to carbon deposition $\left(\mathrm{CH}_{4}(\mathrm{~g}) \rightleftarrows \mathrm{C}(\mathrm{s})+2 \mathrm{H}_{2}(\mathrm{~g}), \Delta \mathrm{H}_{298 \mathrm{~K}}=+75 \mathrm{~kJ} / \mathrm{mol}, 2 \mathrm{CO}(\mathrm{g}) \rightleftarrows \mathrm{C}(\mathrm{s})+\mathrm{CO}_{2}(\mathrm{~g})\right.$, $\Delta H_{298 \mathrm{~K}}=-172 \mathrm{~kJ} / \mathrm{mol}$ ) and making rapid heat supply and quasi-isothermal operation possible. We have also proposed design guidelines for the length in the short axis direction of a cross-sectional rectangle in a single channel, from the viewpoint of taking enough 
mass transfer rate and heat transfer rate to satisfy the reaction rate control $[13,19,22,23]$. However, how to determine the aspect ratio of the cross-section of the flow channel has not been discussed much. That is, the aspect ratio can take from 1 to $\infty$, where the larger the aspect ratio, the lower the pressure drop. On the other hand, it is not clear which aspect ratio is necessary and sufficient.

The purpose of this work is to analyze the aspect ratio in a single rectangle channel on the basis of theoretical equations from the viewpoint of having low frictional resistance. We believe that this contributes to criteria for determining the length in the long axis direction of a cross-sectional rectangle.

Several researchers have validated the theory of pressure drop with experimental results in liquid or gas flow in a void microchannel [24-31]. For example, Kohl et al. carefully discussed friction factors for microchannels with a channel size of 25-100 $\mu \mathrm{m}$ under the wide range of the Reynolds number $(R e), 6.8<R e<18,814$ in compressible flow, and $4.9<R e<2068$ in incompressible flow, respectively [30].

In this study, we investigated the applicability of the analytical solution to the detail system. A comparative study of experimental and computational fluid dynamics (CFD) simulation results for $1 \mathrm{D}$ and $3 \mathrm{D}$ geometries of a tubular reformer reported that satisfactory accuracy was obtained with the 1D model when the relative length (Length/Radius) and residence time were large ( $>15$ and $>8 \mathrm{~kg}_{\text {cat }} \mathrm{s} / \mathrm{mol}_{\mathrm{CH} 4}$, respectively) [32]. The 1D model in our discussion is based on Müller's analytical solution [33]. Müller's solution shows a velocity distribution that has reached a steady state after fully developing laminar flow, where the advection term of the Navier-Stokes equations is set to zero. In the analytical solution, the effect of flow disturbance (e.g., eddies can occur even in laminar flow) due to a large aspect ratio, etc., is not considered. Therefore, although the geometry range and operating conditions are limited, in this study, the analytical solutions are compared not only with experiments but also with 3D-CFD numerical solutions that take the advection term into account.

\section{Methods}

Here, the theory and experimental setup is explained for study of the parameters regarding friction resistance in a single rectangle microchannel.

\subsection{Theory of Pressure Drop}

In this section, we summarize the conventional theory of pressure drop. Equation (1) expresses the fluid force $\left(F_{\mathrm{k}}\right)$ as being proportional to the Fanning friction factor $\left(f_{\mathrm{k}}\right)$, the surface area between the fluid and inner wall $\left(S_{\mathrm{k}}\right)$, and kinetic energy $\frac{1}{2} \rho u^{2}$. In addition, $F_{\mathrm{k}}$ is expressed in another form in Equation (2), which is obtained as the multiplication of the pressure drop $(\Delta p)$ and the channel's cross-sectional area $\left(S_{\mathrm{p}}\right)$. Here, $\rho$ indicates density, and the average flow velocity $\langle u\rangle$ is defined as the flow rate divided by the flow's cross-sectional area.

$$
\begin{gathered}
F_{\mathrm{k}}=f_{\mathrm{k}} S_{\mathrm{k}} \frac{1}{2} \rho u^{2} \\
F_{\mathrm{k}}=\Delta p S_{\mathrm{p}}
\end{gathered}
$$

In this study, $f_{\mathrm{k}}$ is obtained using Equations (1) and (2) using the experimental data of $\Delta p$. When the detailed velocity distribution is known, $f_{\mathrm{k}}$ or $\Delta p$ can be calculated using Equation (3), which is proportional to $S_{\mathrm{k}}$, viscosity $(\mu)$, and the velocity gradient $\frac{\mathrm{d} u_{\mathrm{z}}}{\mathrm{dr}_{\perp}} \cdot \tau_{\mathrm{w}}$ indicates the shear stress subjected to the channel wall and is expressed as $-\mu \frac{d u_{\mathrm{z}}}{d r_{\perp}}$ based on Newton's law of viscosity.

$$
F_{\mathrm{k}}=\tau_{\mathrm{w}} S_{\mathrm{k}}=-\mu \frac{d u_{\mathrm{z}}}{d r_{\perp}} S_{\mathrm{k}}
$$

One of the results of the dimension analysis indicates that $f_{\mathrm{k}}$ is a function of $R e$. Theoretically, $f_{\mathrm{k}}$ under the laminar flow state is $16 / R e$ in a circular cross-section channel and $14.2 / R e$ in a square cross-section channel, respectively. $f_{\mathrm{k}}$ is an index of the ease of 
pressure drop occurrence; however, it can be said that $f_{\mathrm{k}} \cdot \frac{S_{\mathrm{k}}}{S_{\mathrm{p}}}$ is a more reasonable index of frictional resistance because it is a proportionality factor for kinetic energy, $\frac{1}{2} \rho u^{2}$ in pressure drop $(\Delta p)$ equation. $f_{\text {Darcy }} \equiv f_{\mathrm{k}} \cdot \frac{S_{\mathrm{k}}}{S_{\mathrm{p}}} \cdot \frac{d_{\mathrm{H}}}{L}=4 f_{\mathrm{k}}$ is the so-called Darcy friction factor, where $\frac{S_{\mathrm{k}}}{S_{\mathrm{p}}}=4 \frac{L}{d_{\mathrm{H}}}$. In this work, we continue discussions using the Fanning friction factor for separating the effect of $\frac{S_{\mathrm{k}}}{S_{\mathrm{p}}}$ and $\frac{d_{\mathrm{H}}}{L}$.

Müller presented analytical solutions for the velocity distribution and friction coefficient for different cross-sectional shapes by solving the Navier-Stokes equation [33]. The velocity distribution and the pressure drop equation for the rectangular flow channel studied here are expressed in Equations (4) and (5), respectively, where $K$ is expressed in Equation (6). Here, the coordinate origin is the center of the rectangle, and when the coordinate in the long side direction is represented by $x$ and that of the short side direction is represented by $y$, the rectangle of the channel's cross-section is depicted as the region of $-a \leq x \leq a$ and $-b \leq y \leq b . L$ indicates the channel length in the flow direction.

$$
\begin{gathered}
u(x, y)=\frac{\Delta p}{\mu L}\left[\frac{1}{2}\left(b^{2}-y^{2}\right)+\frac{16 b^{2}}{\pi^{3}} \sum_{n=1}^{\infty} \frac{(-1)^{n}}{(2 n-1)^{3}} \cos \frac{(2 n-1) \pi y}{2 b} \frac{\cosh \frac{(2 n-1) \pi x}{2 b}}{\left.\cosh \frac{(2 n-1) \pi a}{2 b}\right]}\right. \\
\Delta p=\frac{16 \mu L\langle u\rangle}{b^{2} K} \\
K=\frac{16}{3}-\frac{1024}{\pi^{5}} \frac{b}{a} \sum_{n=1}^{\infty} \frac{1}{(2 n-1)^{5}} \tanh \frac{(2 n-1) \pi a}{2 b}
\end{gathered}
$$

For example, when $\Delta p$ is known, the velocity distribution can be estimated from Equation (4). By defining the Reynolds number as $R e \equiv \frac{\rho d_{\mathrm{H}} u}{\mu}$ using the hydraulic diameter $\left(d_{\mathrm{H}}=4 \cdot \frac{a b}{a+b}\right.$ or $\left.4 \cdot \frac{\text { cross-sectionnal area }}{\text { wetted perimeter }}\right)$ as the representative channel size, Equation (7) can be obtained as an expression of $f_{\mathrm{k}}$ for the rectangular channel.

$$
f_{\mathrm{k}}=\frac{16}{\operatorname{Re}} \frac{8 a^{2}}{(a+b)^{2} \mathrm{~K}}
$$

\subsection{CFD Simulation}

We conducted numerical simulation by commercial CFD code $\mathrm{COMSOL}^{\circledR}$ using laminar flow model of Navier-Stokes equation (Equations (8) and (9)) in the steady-state analysis to see the consistency with the theory (Equations (4)-(6)) or experiment. Even under a laminar flow condition with a low Re number, the flow may be separated and flow disturbances such as vortices may occur in the flow path under a high-aspect-ratio channel.

Here, fluid of gas was treated as incompressible fluid, because the experiments described below were conducted at a Mach number less than 0.3 and under $101 \mathrm{kPa}$ and room temperature.

$$
\begin{gathered}
\rho(\mathbf{u} \cdot \nabla) \mathbf{u}=\nabla \cdot\left[-p \mathbf{I}+\mu\left(\nabla \mathbf{u}+(\nabla \mathbf{u})^{\mathrm{T}}\right)\right] \\
\rho \nabla \cdot(\mathbf{u})=0
\end{gathered}
$$

The analytical solutions (Equations (4)-(6)) are those in which the advection term on the left-hand side of Equation (8) is set to zero.

The physical properties of helium used in experiments were set as $\mu=2.0 \times 10^{-5} \mathrm{~Pa} \cdot \mathrm{s}$, $\rho=0.166 \mathrm{~kg} \mathrm{~m}^{-3}$. The flow rate was set within the range of 0 to $1.67 \times 10^{-5} \mathrm{Nm}^{3} \mathrm{~s}^{-1}$ $\left(=0-1000 \mathrm{~mL}_{\mathrm{stp}} / \mathrm{min}\right.$, and the flow path size of the rectangular was set as $(2 a, 2 b, L)=$ $\left(0.9 \times 10^{-3} \mathrm{~m}\right.$ to $7 \times 10^{-3} \mathrm{~m}$, about $\left.0.4 \times 10^{-3} \mathrm{~m}, 0.26 \mathrm{~m}\right)$. The aspect ratio, $\frac{a}{b}$, ranged from 1 to 20. The calculation area was three-dimensional (3D) shown in Figure 1a. The entrance or exit of the fluid was a $2 a \times 2 b$ section, and the flow path was assumed to be $2 a \times 2 b \times L$. 
(a)

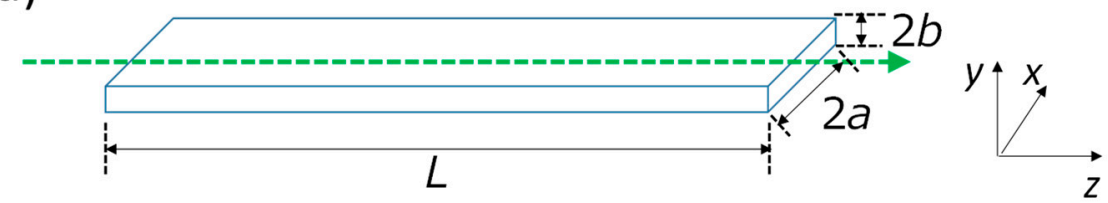

(b) Plates

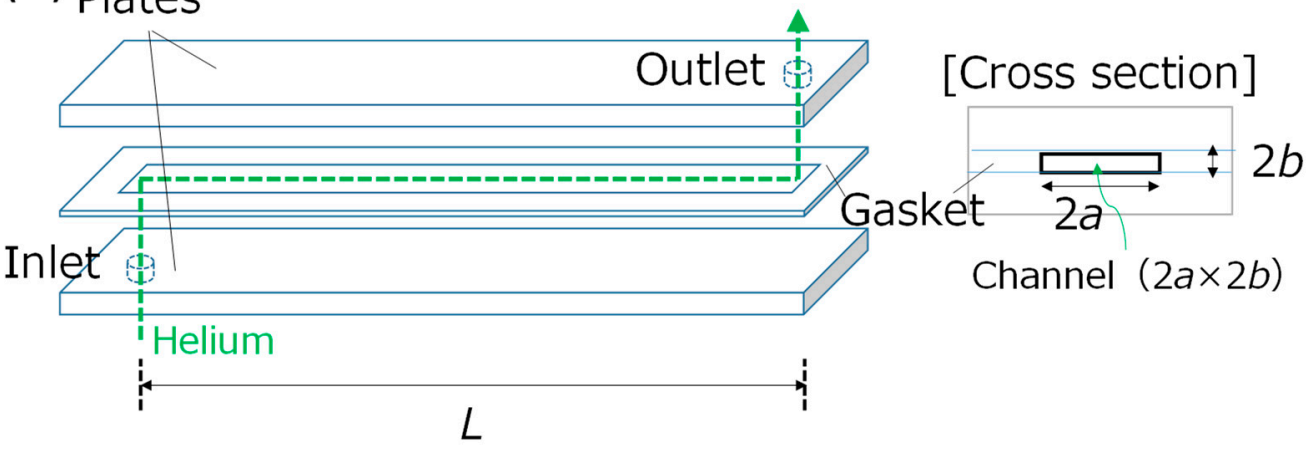

(c)

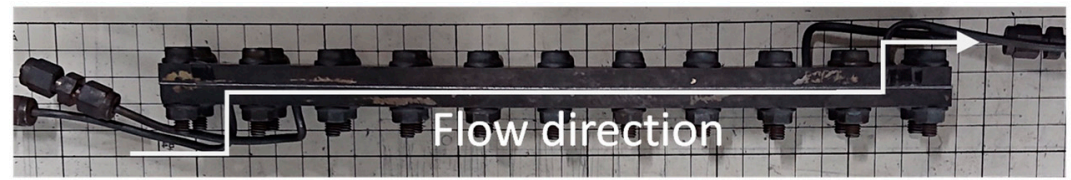

(d)

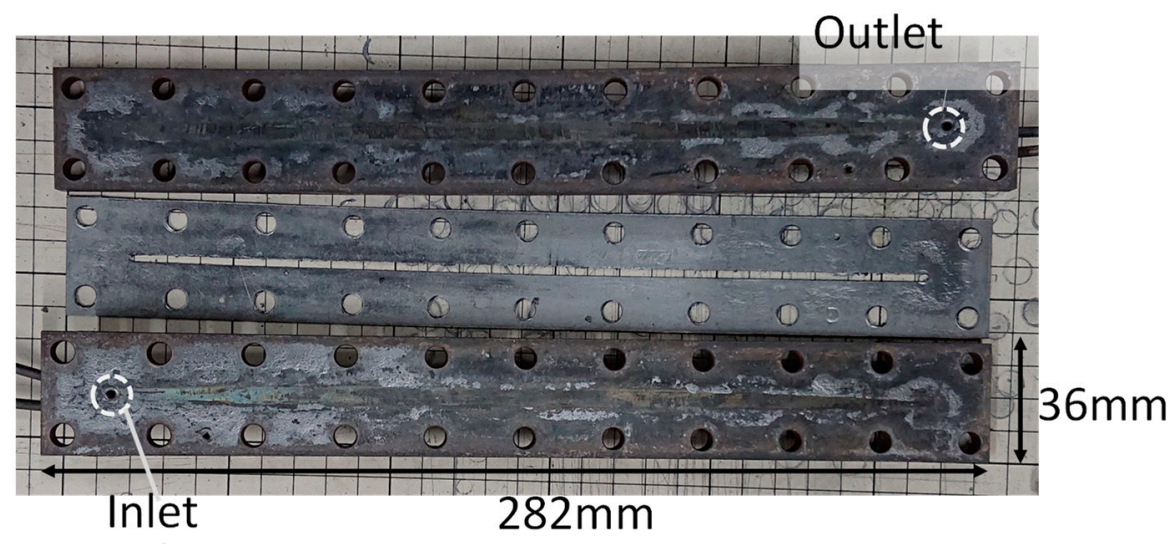

(e)

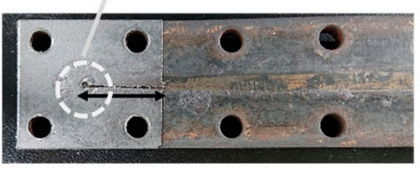

\section{$20 \mathrm{~mm}$}

Figure 1. Structure of plate reactor with a rectangular channel: (a) geometry for 3D CFD simulation, (b) perspective view of the device used in the experiment, (c) an assembled plate reactor used in this work, (d) stainless steel plates and gasket with the rectangular slit before assembling, (e) cut gasket for measurements of fluid resistance at the inlet and the outlet.

Boundary conditions were as follows:

Laminar flow at the inlet. (Approach distance was $1 \mathrm{~m}$ ).

Backflow prevention at the outlet.

No slip $(\mathbf{u}=\mathbf{0})$ at the channel inner walls.

Mesh quality was determined from sensitivity analysis until convergence within $\pm 5 \%$ was "too fine" in a function of COMSOL ${ }^{\circledR}$, where mesh size took the range of $1.12 \times 10^{-5}-1.03 \times 10^{-4} \mathrm{~m}$, and boundary layer was set in 8 layers. 


\subsection{Experimental}

Authors used the plate reactor shown in Figure $1 \mathrm{~b}-\mathrm{e}$, which was the same used in reaction tests reported in previous works $[16,23,34]$. The flexible carbon gasket, with a rectangular slit functioning as the flow path, was sandwiched between two stainless steel plates and fastened with bolts and nuts. Here, the size of the rectangular flow path was fixed at $L=0.26 \mathrm{~m}$ and experiments were conducted within the range of $\left(2 a, 2 b, \frac{a}{b}\right)=(0.9-7.0 \mathrm{~mm}$, ca. $0.4 \mathrm{~mm}, 2.25-18.4)$. In detail, there were eight types of flow path sizes: $\left(2 a, 2 b, \frac{a}{b}\right)=$ $(0.9 \mathrm{~mm}, 0.4 \mathrm{~mm}, 2.25),(1.4 \mathrm{~mm}, 0.4 \mathrm{~mm}, 3.5),(1.8 \mathrm{~mm}, 0.38 \mathrm{~mm}, 4.74),(2.4 \mathrm{~mm}, 0.36 \mathrm{~mm}$, 6.67), (3.0 mm, $0.36 \mathrm{~mm}, 8.33),(4.0 \mathrm{~mm}, 0.38 \mathrm{~mm}, 10.5),(5.2 \mathrm{~mm}, 0.4 \mathrm{~mm}, 13)$, and $(7.0 \mathrm{~mm}$, $0.38 \mathrm{~mm}, 18.4)$.

Experimental setup is shown in Figure 2. Helium was used as flow fluid under standard temperature and pressure conditions (room temperature ca. $25^{\circ} \mathrm{C}$ and ca. $101 \mathrm{kPa}$ ). The pressure drop was measured using a pressure gauge (GPM-010, Keyence Corp., Osaka, Japan. The measurement error is within $\pm 1 \%$.), and the gas flow rate was measured using a volumetric flowmeter (ADM1000, Agilent Technologies, Inc., Santa Clara, CA, USA. The measurement error is within $\pm 3 \%$ ). The channel's surface was observed using an optical microscope (VHX-series, Keyence Corp., Osaka, Japan). Before pressure measurements, the reactor's sealability tests were conducted until the gas leaks within $\pm 1 \%$ were obtained.

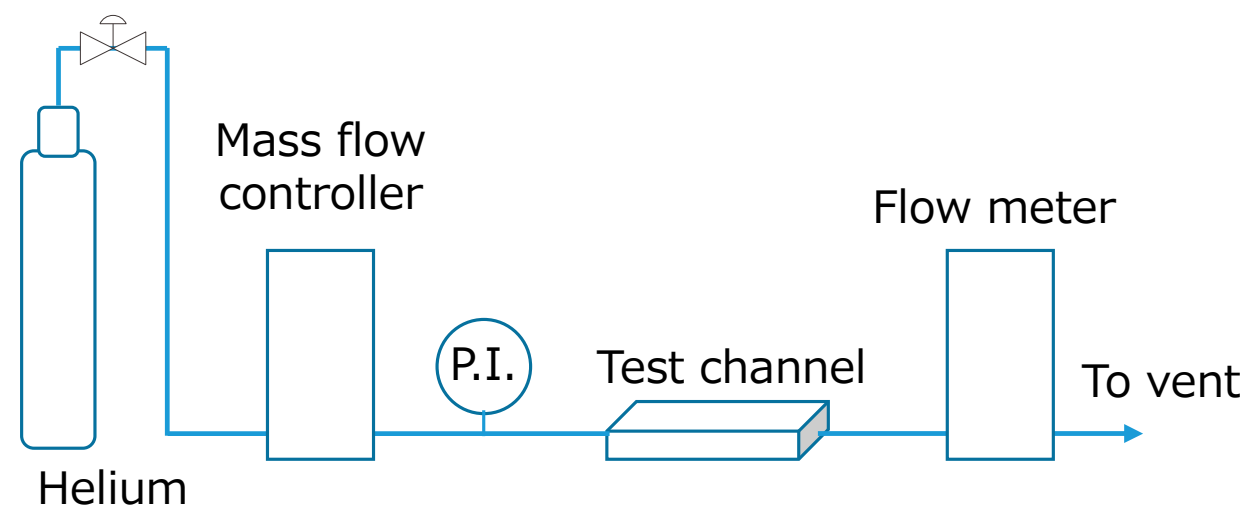

Figure 2. Experimental setup.

Since the influence of fluid resistance on the pressure drop at the bend of the inlet and the outlet can be considered, as depicted in Figure $1 b, c$, the pressure drop loaded at bend of both the inlet and the outlet was measured using separately prepared gasket cut to $20 \mathrm{~mm}$ from the inlet or outlet as shown in Figure 1e. By subtracting the pressure drop at the bend of both the inlet and the outlet from that of the assembled plate reactor, including bend channel, we obtained the compensate pressure drop of a straight rectangle channel (ideal geometry is shown in Figure 1a).

\section{Results and Discussion}

First, we will discuss the theoretical formula of pressure drop for the representative cross-sectional shapes and compare them using dimensionless formulas. Second, for the rectangular flow path, we will consider the aspect ratio for the low pressure drop.

The results will be compared with detailed computational solutions using 3D-CFD and experimental results.

\subsection{Analysis of the Theoretical Equations}

Here, $\langle u\rangle, L$, and the flow path height $(d(=2 b))$ are fixed. We assume the case that $d$, the length in the short axis direction of the cross-section in a single rectangle channel, is decided as a necessarily short length for a high enough mass and heat transfer rate to satisfy the reaction rate control. This corresponds to the problem of determining the interval of rectangle channels $(=2 a)$ installed in a plate reactor in the $x$ direction after determining 
$d(=2 b)$. Here, $d$ is unified as the channel's height among different cross-sectional shapes, as shown in Figure 3.

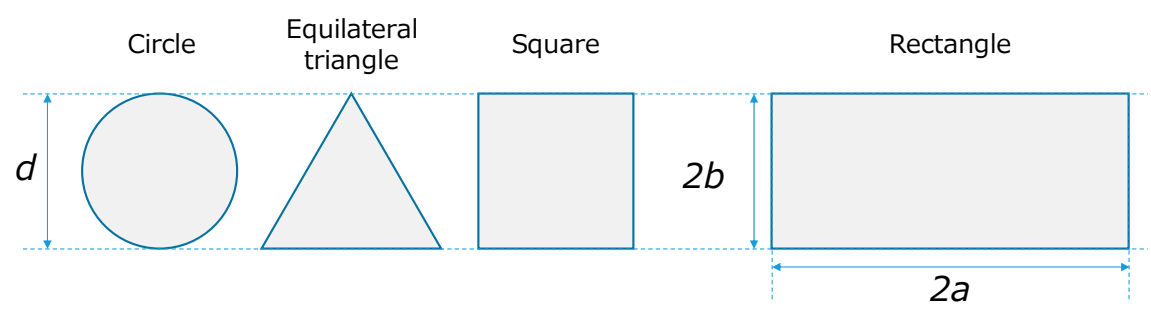

Figure 3. Channel's cross-section and size of each duct shape.

A list of parameters related to each flow path shape is shown in Table 1 (Müller showed not only each friction factor, but also analytical velocity distribution and volumetric flow rate [33]).

Table 1. Parameters regarding pressure drop of each cross-sectional shape.

\begin{tabular}{|c|c|c|c|c|c|c|c|}
\hline & $S_{\mathrm{k}}$ & $S_{\mathrm{p}}$ & $\frac{S_{k}}{S_{p}}$ & $d_{\mathrm{H}}$ & $f_{\mathrm{k}}$ & $\operatorname{Re}$ & $f_{k} \cdot \frac{S_{k}}{S_{p}}$ \\
\hline Circle & $\pi d L$ & $\frac{\pi d^{2}}{4}$ & $\frac{4}{d} L$ & $d$ & $\frac{16}{R e}$ & $\frac{\rho d u}{\mu}$ & $64 \frac{L}{d} \frac{1}{R e}=64 \frac{L}{d} \frac{\mu}{\rho d u}$ \\
\hline $\begin{array}{l}\text { Equilateral } \\
\text { triangle }\end{array}$ & $\sqrt{3} d L$ & $\frac{d^{2}}{\sqrt{3}}$ & $\frac{3}{d} L$ & $\frac{4}{3} d$ & $\frac{40}{3} \frac{1}{R e}$ & $\frac{4}{3} \frac{\rho d u}{\mu}$ & $40 \frac{L}{d} \frac{1}{R e}=30 \frac{L}{d} \frac{\mu}{\rho d u}$ \\
\hline Square & $4 d L$ & $d^{2}$ & $\frac{4}{d} L$ & $d$ & $\frac{14.2}{R e}$ & $\frac{\rho d u}{\mu}$ & $56.89 \frac{L}{d} \frac{1}{R e}=56.89 \frac{L}{d} \frac{\mu}{\rho d u}$ \\
\hline Rectangle & $2 d\left(1+\frac{a}{b}\right) L$ & $d^{2} \frac{a}{b}$ & $\frac{2}{d} \frac{\left(1+\frac{a}{b}\right)}{\frac{a}{b}} L$ & $2 d \frac{\frac{a}{b}}{\left(1+\frac{a}{b}\right)}$ & $\frac{16}{\operatorname{Re}} \frac{8\left(\frac{a}{b}\right)^{2}}{\left(1+\frac{a}{b}\right)^{2} K}$ & $\frac{2 \frac{a}{b}}{\left(1+\frac{a}{b}\right)} \frac{\rho d u}{\mu}$ & $\frac{256}{K} \frac{\frac{a}{b}}{1+\frac{a}{b}} \frac{L}{d} \frac{1}{R e}=\frac{128}{K} \frac{L}{d} \frac{\mu}{\rho d u}$ \\
\hline
\end{tabular}

In the rectangular channel, the proportional coefficient in $f_{\mathrm{k}}$ becomes a complicated function of $\frac{a}{b}$, including the series shown in Equation (6). $f_{\mathrm{k}} \cdot \operatorname{Re}$ takes a value ranging from 14.2 to 24 with a positive correlation under $1<\frac{a}{b}<\infty$.

$\Delta p$ also depends on the channel-specific surface area, $\frac{S_{k}}{S_{p}}$, so it is appropriate to compare the modulus given as $f_{\mathrm{k}} \cdot \frac{S_{\mathrm{k}}}{S_{\mathrm{p}}}$. When $\langle u\rangle, L$, and $d$ are fixed, $f_{\mathrm{k}} \cdot \frac{S_{\mathrm{k}}}{S_{\mathrm{p}}}$ is the index of the ease of pressure drop occurrence. The descending order of the proportional constant of each cross-sectional shape in $f_{\mathrm{k}} \cdot \frac{S_{\mathrm{k}}}{S_{\mathrm{p}}}$ is as follows: 64 (circle) $>56.89$ (square) $>30$ (equilateral triangle). For the rectangle, the proportional constant in $f_{\mathrm{k}} \cdot \frac{S_{\mathrm{k}}}{S_{\mathrm{p}}}$ takes $24 \sim 56.89$, and when the value of $\frac{a}{b}$ is set above 3.15 , where $K$ takes more than 4.27 , the proportional constant in $f_{\mathrm{k}} \cdot \frac{S_{\mathrm{k}}}{S_{\mathrm{p}}}$ is smaller than 30 of the equilateral triangle's. Under the condition that $\langle u\rangle, L$ and $d$ are fixed, it can be said that the rectangle channel has the smallest frictional resistance.

$\Delta p$ is proportional to $\frac{128}{K}$ (See the column of $f_{\mathrm{k}} \cdot \frac{S_{\mathrm{k}}}{S_{\mathrm{p}}}$ in Table 1). Since $K$ is a function of $\frac{a}{b}, \Delta p$ substantially depends on $\frac{a}{b}$. The trends of parameters related to $\frac{a}{b}$ are summarized in Figure 4.

According to Figure 4 , since $f_{\mathrm{k}} \cdot \frac{d d u}{\mu} \cdot \frac{S_{\mathrm{k}}}{S_{\mathrm{p}}} \cdot \frac{d}{L}\left(=\frac{128}{K}\right)$ monotonously decreases with respect to $\frac{a}{b}$, this also contributes to the monotonical decrease in $\Delta p$. Focusing on each of the divided parameters, $\frac{S_{\mathrm{k}}}{S_{\mathrm{p}}} \cdot \frac{d}{L}$ decreases monotonically in the same way, whereas $f_{\mathrm{k}} \cdot \frac{\rho d u}{\mu}$ is found to have a local minimum value of ca. 11.4 when $\frac{a}{b}$ is ca. 3.40 . That is, $f_{\mathrm{k}} \cdot \frac{\rho d u}{\mu} \cdot \frac{S_{\mathrm{k}}}{S_{\mathrm{p}}} \cdot \frac{d}{L}$ decreases monotonically and mitigates moderately when $\frac{a}{b}$ takes more than ca. 3.40. Therefore, as a condition for ensuring a low pressure drop, $\Delta p$, it is theoretically recommended that the aspect ratio, $\frac{a}{b}$, takes ca. 3.40 at least. The upper limit of $\frac{a}{b}$ should be determined from the request of structural strength and/or flow uniformity, which especially affects reaction performance when scaling up. 

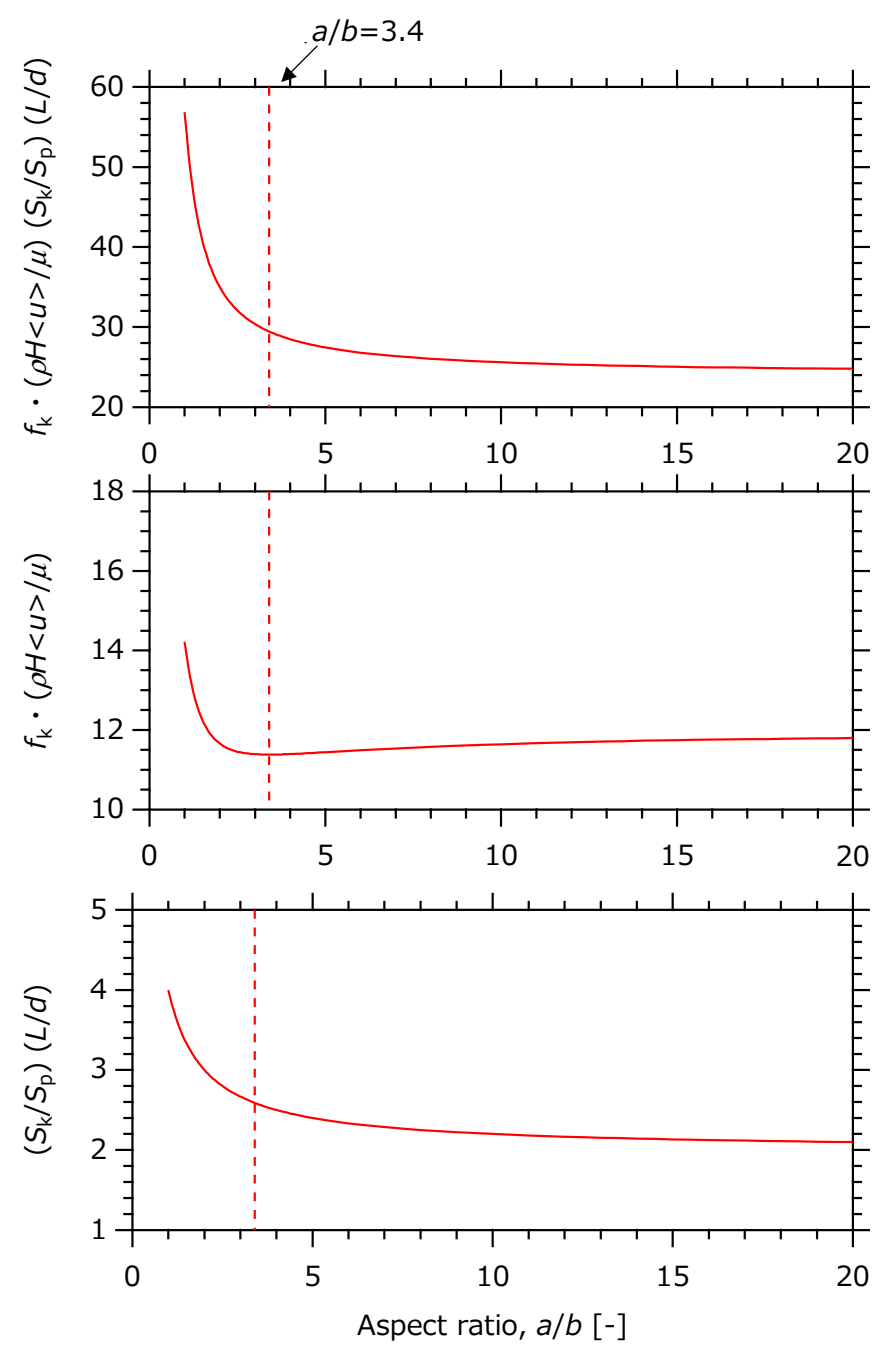

Figure 4. Aspect ratio dependence of dimensionless modulus related to pressure drop in analytical solution.

Incidentally, there is another definition known as the Darcy friction factor of $f_{\text {Darcy }} \equiv f_{\mathrm{k}} \cdot \frac{S_{\mathrm{k}}}{S_{\mathrm{p}}} \cdot \frac{d_{\mathrm{H}}}{L}=4 f_{\mathrm{k}}$. Table 1 shows that $f_{\text {Darcy }}$ 's proportional constant is 64 for a circle, 40 for an equilateral triangle, and 56.89 for a square. For the rectangle, the proportional constant, $\frac{256}{K} \frac{\frac{a}{b}}{1+\frac{a}{b}}$, takes 56.89 at $\frac{a}{b}=1$ (square channel) and 48 at $\frac{a}{b}=\infty$ (parallel slit channel), and it takes a local minimum value of ca. 45.5 at $\frac{a}{b} \approx 3.40$.

\subsection{Comparison between the Analitical Solution and the Results of the Detailed Systems}

Figure 5 shows the analytical velocity distribution obtained from Equation (4). Figure $5 \mathrm{a}, \mathrm{b}$, where $\frac{a}{b}$ of each line is $1,2,4,6,8,10$ in order from inside to outside, shows that dimensionless velocity in the center of the channel (in the figure's $y$-direction) increases from 0.3 to 0.5 with $\frac{a}{b}$ increasing from 1 to 4 . This is due to the effect of friction along the walls, which decreases with an increase in the aspect ratio; in other words, low aspect ratio takes a relatively large pressure drop. For example, Figure $5 \mathrm{c}$ shows the $3 \mathrm{D}$ velocity distribution of $\left(2 a, 2 b, \frac{a}{b}\right)=(2.4 \mathrm{~mm}, 0.36 \mathrm{~mm}, 6.67)$ and $\Delta p=2.93 \mathrm{kPa}$, which is one of the experimental conditions. The velocity in the long side direction is almost constant, except for near the wall surface, and the 3D velocity distribution appears to be spatula-like in shape. In ca. $4<\frac{a}{b}$, the velocity distribution changes from a parabolic distribution to a flat distribution with a tip close to the plug flow, and a reaction performance similar to that of a plug flow reactor is expected. 
(a)

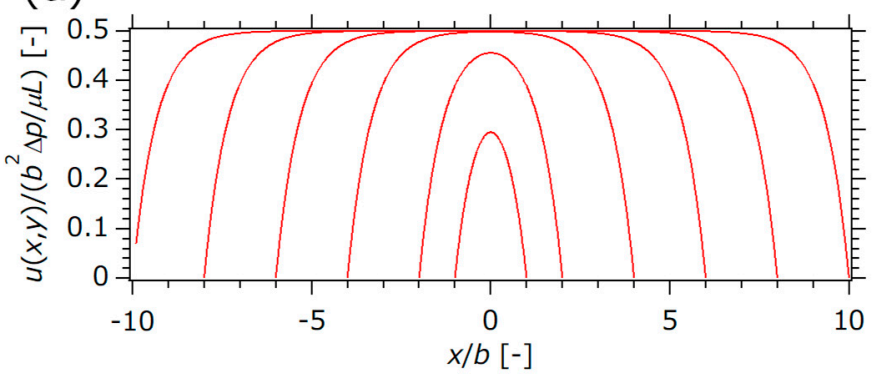

(b)

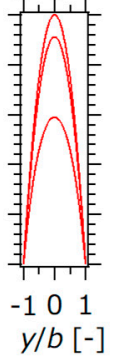

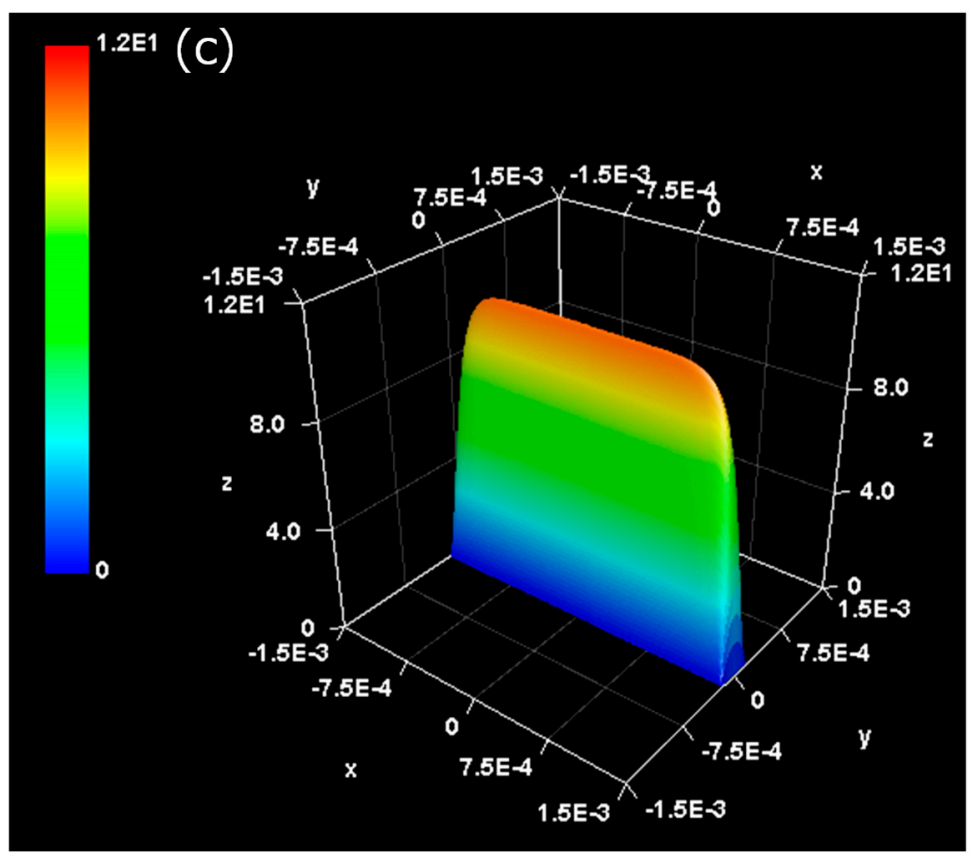

Figure 5. Analytical velocity distributions of rectangle channel: (a) dimensionless velocity in long side direction, (b) dimensionless velocity in short side direction, (c) 3D view of $\left(2 a, 2 b, \frac{a}{b}\right)=(2.4 \mathrm{~mm}$, $0.36 \mathrm{~mm}, 6.67)$ and $\Delta p=2.93 \mathrm{kPa}$. $\frac{a}{b}$ of each line is $1,2,4,6,8,10$ in order from inside to outside in $(\mathbf{a}, \mathbf{b})$.

At large aspect ratios, there is concern about deviation from an elaborate laminar flow, due to vortex generation or flow separation from the walls. The relation between flow rate and pressure drop under the same operational conditions is depicted in Figure 6. Figure $6 c$ shows parity plots constructed from the data in Figure $6 \mathrm{a}, \mathrm{b}$. A difference of obtained $\Delta p$ between CFD and experimental was within $+28 \%$, and also that obtained between CFD and theory was within $+3 \%$ at $2.25<\frac{a}{b}<13$. The latter error is within the measurement error range of the flow meter, and no clear disturbances such as vortices were observed in the streamlines on the CFD. Here, the study conducted was under a laminar flow regime in low Re up to 150 .

Microscopic observation showed that the absolute roughness in the short side direction of the rectangular channel had a maximum value of $25 \mu \mathrm{m}$, and the equivalent relative roughness $\varepsilon / D$ had a maximum value of about 0.07 (Figure 7). According to the Moody chart [35], the friction factor increases ca. $+30 \%$ at $\frac{\varepsilon}{D}=0.07$, compared to that of the smooth wall. The difference between the measured pressure drop and the calculated pressure drop is within the range of the pressure increase due to surface roughness. 


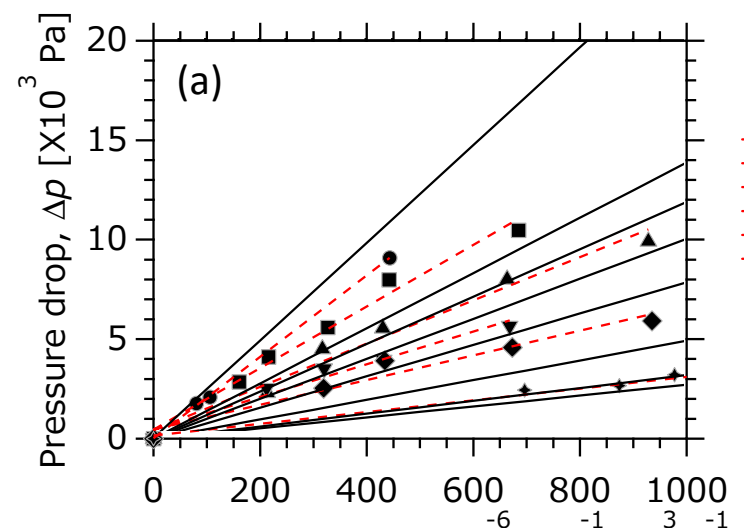

mark $(2 a, 2 b, a / b)$ :

$\stackrel{0}{\bullet}(0.9 \mathrm{~mm}, 0.4 \mathrm{~mm}, 2.25) \quad \diamond(3.0 \mathrm{~mm}, 0.36 \mathrm{~mm}, 8.33)$

- $(1.4 \mathrm{~mm}, 0.4 \mathrm{~mm}, 3.5) \quad \diamond(4.0 \mathrm{~mm}, 0.38 \mathrm{~mm}, 10.5)$

$\triangle(1.8 \mathrm{~mm}, 0.38 \mathrm{~mm}, 4.74) \stackrel{\diamond}{\Delta}(5.2 \mathrm{~mm}, 0.4 \mathrm{~mm}, 13)$

$\nabla(2.4 \mathrm{~mm}, 0.36 \mathrm{~mm}, 6.67) \quad \square(7.0 \mathrm{~mm}, 0.38 \mathrm{~mm}, 18.4)$

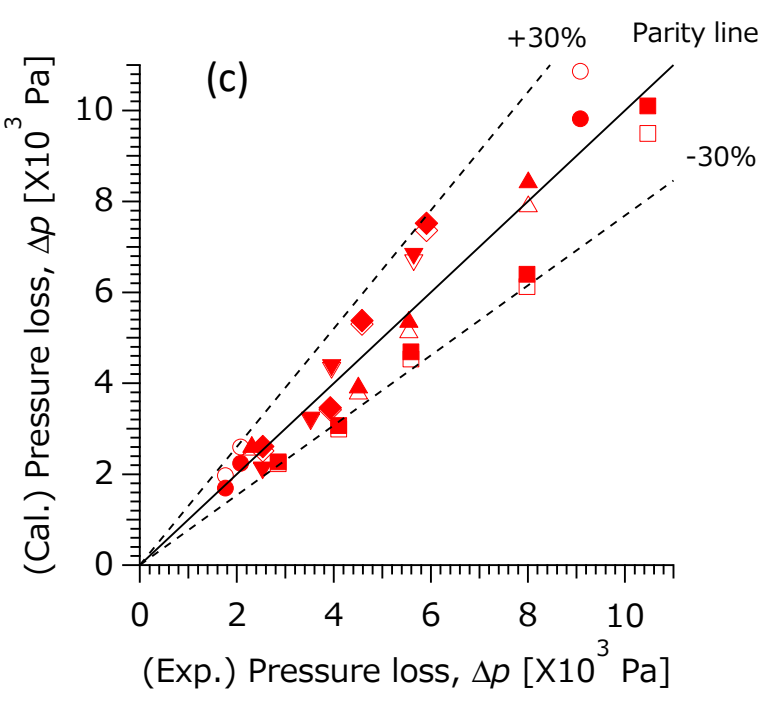

Figure 6. (a,b) Profiles of pressure drop against flow rate of inlet. Filled black: experiment, filled gray: CFD, solid line: analytical solution. (c) Parity plots. Filled red: Exp.-Cal.(1D) (= analytical solution), blank: Exp.-Cal.(3D) (=CFD). Circle: $(2 a, 2 b, a / b)=(0.9 \mathrm{~mm}, 0.4 \mathrm{~mm}, 2.25)$, square: $(1.4 \mathrm{~mm}, 0.4 \mathrm{~mm}, 3.5)$, triangle: $(1.8 \mathrm{~mm}, 0.38 \mathrm{~mm}, 4.74)$, upside-down triangle: (2.4 mm, $0.36 \mathrm{~mm}, 6.67)$, diamond: (3.0 mm, $0.36 \mathrm{~mm}, 8.33)$, pentagon: (4.0 mm, $0.38 \mathrm{~mm}, 10.5)$, cross (5.2 mm, $0.4 \mathrm{~mm}, 13)$, $\times$-mark: $(7.0 \mathrm{~mm}, 0.38 \mathrm{~mm}, 18.4)$.

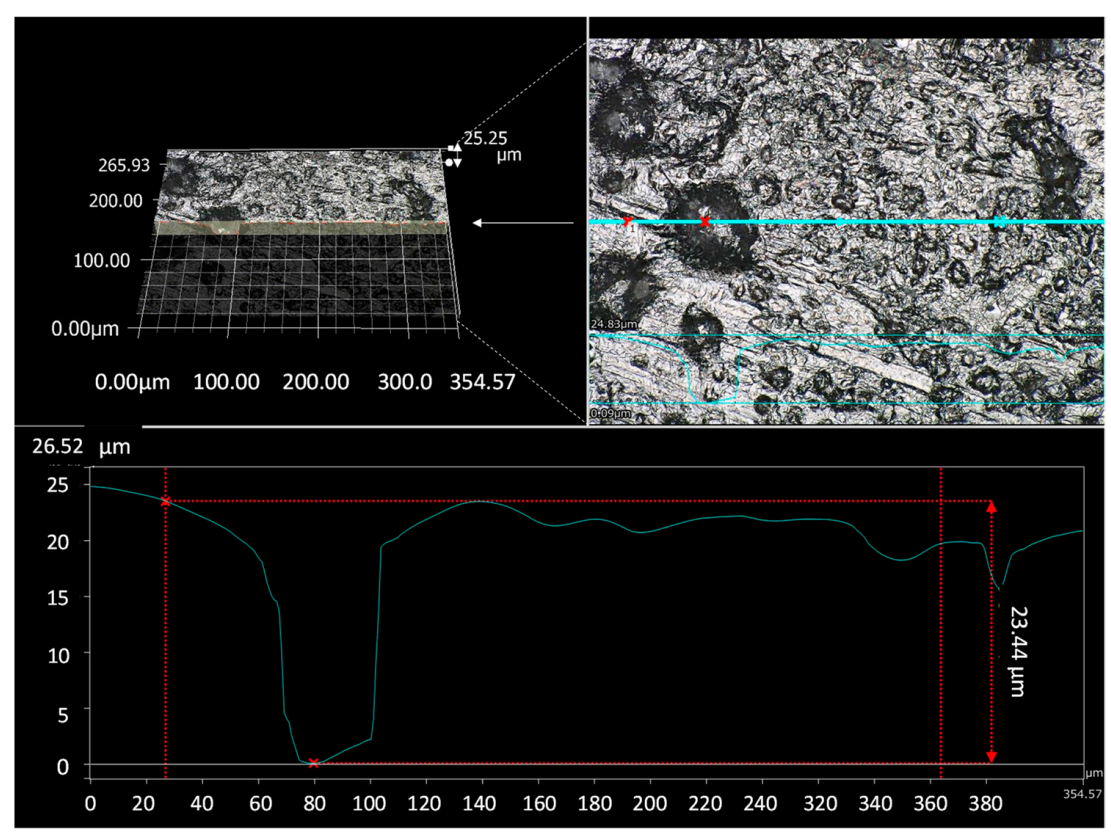

Figure 7. Roughness observed by optical microscope; (upper left) bird's-eye view, (upper right) enlarged image, (under) roughness of the cross section. 
Figure 8a shows the relation between $\frac{a}{b}$ and $f_{\mathrm{k}} \cdot R e$, which allows to compare the results of CFD calculation with those of the experiment. Re is calculated using the rectangle's definition shown in Table 1 , and $f_{\mathrm{k}}$ is calculated by dividing $\Delta p$ by $\frac{1}{2} \rho\langle u\rangle^{2} \frac{S_{\mathrm{k}}}{S_{\mathrm{p}}}$ based on Equations (1) and (2). The theoretical value of $f_{\mathrm{k}} \cdot \operatorname{Re}$ obtained from the expression in Table 1 is also described
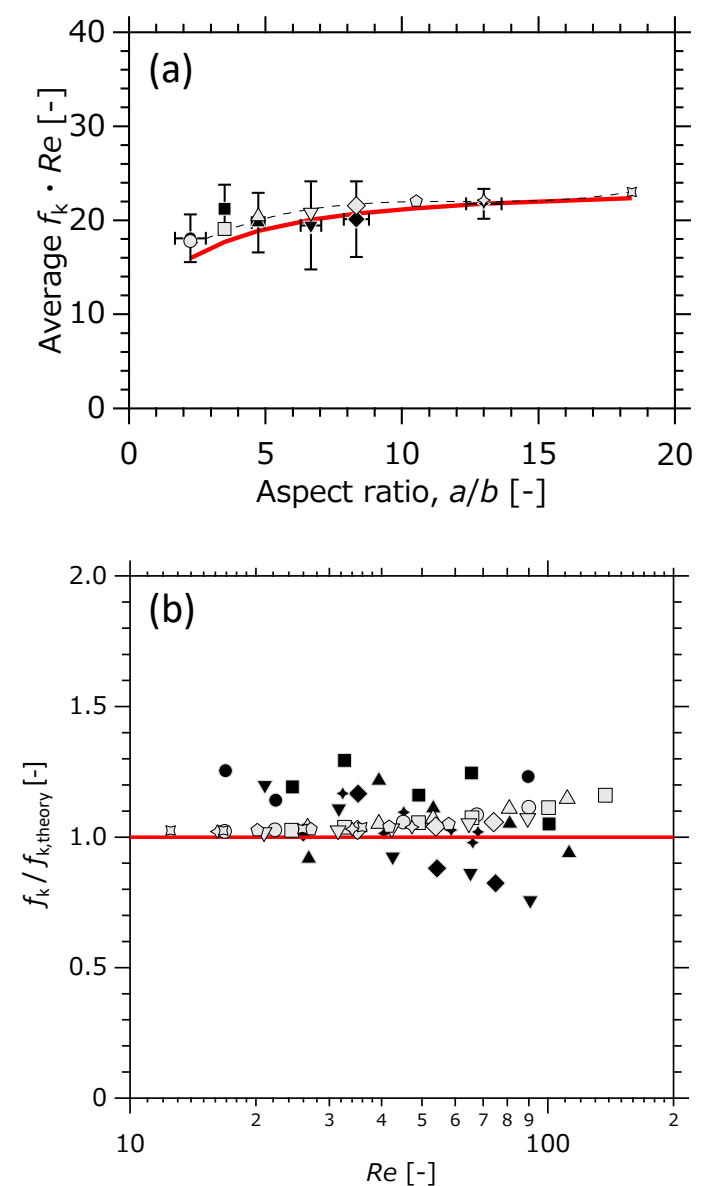

(c)

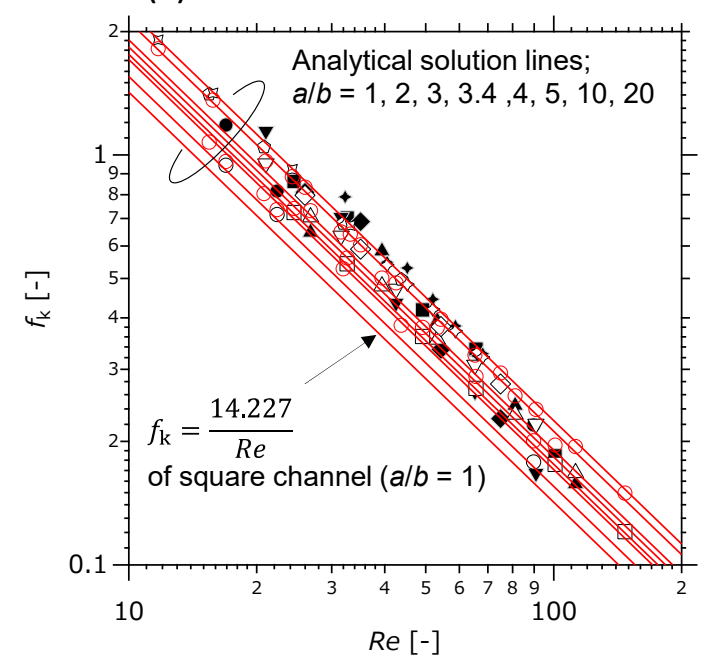

Figure 8. (a) relation between $\frac{a}{b}$ and $f_{\mathrm{k}} \cdot R e$, (b) tendency of $f_{\mathrm{k}}$ and its error against $R e$; Re vs. $f_{\mathrm{k}} / f_{\mathrm{k}, \text { theory }}$ (c) Re vs. $f_{\mathrm{k}}$. Filled black: experiment, filled gray: CFD (3D cal.), blank mark or solid line: analytical solution (1D cal.). The notation of the keys follows Figure 6. 
The results of CFD simulations are in general agreement with the analytical solution, suggesting that there is a certain validity in applying the theoretical equations in Equations (4)-(6) to the design of the aspect ratio of the rectangle channel. The larger $a / b$ is, the smaller the error between them tends to be. Pashchenko reported that the calculation results of $1 \mathrm{D}$ and $3 \mathrm{D}$ models agree well with each other when the relative length (Length/Radius) is greater than 15 and the residence time is more than $8 \mathrm{~kg}_{\text {cat }}$ $\mathrm{s} / \mathrm{mol}_{\mathrm{CH} 4}$ [32]. In the present study, a larger $a / b$ means a larger rectangular cross-sectional area of the flow channel. When $a / b$ takes from 2.25 to 18.4 , relative length $\left(L /\left(d_{\mathrm{H}} / 2\right)\right)$ takes from 939 to 721 , and residence time takes $\left(=\left[\mathrm{L} \mathrm{s} / \mathrm{mol}_{\mathrm{He}}\right]\right)$ from 1.89 to 13.9. According to Pashchenko's criteria, the relative length of this study is large enough. Regarding the agreement between the calculated results of the 1D and 3D models, it can be inferred that the inferiority at low $a / b$ and the superiority at high $a / b$ is due to residence time.

The deviation between the experimental and theoretical values was within $\pm 7 \%$ at $4.74<\frac{a}{b} \cdot f_{\mathrm{k}} \cdot \operatorname{Re}$ has the tendency to converge to theoretical value. To consider whether these errors are due to the flow state or not, $f_{\mathrm{k}}$ is plotted against Re in Figure $8 \mathrm{~b}, \mathrm{c}$. Figure $8 \mathrm{~b}$ is a plot of the ratio of friction factor calculated from the obtained $\Delta p$ to the theoretical friction factor defined in Table 1. $\frac{f_{\mathrm{k}}}{f_{\mathrm{k}, \text { theory }}}$ has little dependency on the Re number. The error of about $\pm 30 \%$ is due to the roughness of the channel surface, and is considered to be within the reasonable range.

According to the previous reports, even in the microchannel, the transition from a laminar to turbulent flow regime is observed from at least $R e \approx 200$ and up to $2300[24,25,30,36]$. In the present study, there was little transient behavior of $f_{\mathrm{k}}$ against $10<\operatorname{Re}<120$, as shown in Figure 8c.

\section{Summary}

From the theoretical consideration, it was clarified that $3.40<\frac{a}{b}$ is recommended as a criterion for determining the aspect ratio from the viewpoint of reducing frictional resistance of the rectangular cross-sectional channel, where $\langle u\rangle, d(=2 b)$, and $L$ are predetermined. This addresses the problem of determining the interval of rectangle channels $(=2 a)$, installed in a plate reactor. There is a concern that the actual system will not follow the analytical solution assuming laminar flow, because the advection term is assumed to be zero in the analytical solution, and as the aspect ratio increases, flow disturbances such as vortex generation will occur. However, in the volume range of $(2 a, 2 b, L)=(7.0 \mathrm{~mm}$, $0.38 \mathrm{~mm}, 0.26 \mathrm{~m}$ ), the results of both the analytical and CFD simulations agreed within $3 \%$ accuracy. The results also agreed with the experimental system to an accuracy of $\pm 30 \%$ in frictional resistance, which was within a deviation corresponding to about $7 \%$ of the surface roughness.

We believe that the concept of taking a low pressure drop at $3.40<\frac{a}{b}$ derived from theoretically can be also applied to not only the gas-phase system but also the liquid-phase system. It would also be interesting to apply it to multi-phase systems. In addition, there is room for verification as to whether an analytical solution holds in a very long flow path, which was not dealt with this time. These are works for the future.

Author Contributions: Conceptualization, T.F.; methods, T.F.; software support, T.F.; experiment validation, T.F.; manuscript preparation, T.F.; writing —original draft preparation, T.F.; writingreview and editing, M.R.H.; supervision, M.R.H. All authors have read and agreed to the published version of the manuscript.

Funding: This research was funded by the Japan Society for the Promotion of Science (JSPS) KAKENHI Grant Number 15K18263.

Data Availability Statement: The data that presented in this study are available from the corresponding author, upon reasonable request.

Conflicts of Interest: The authors declare no conflict of interest. 


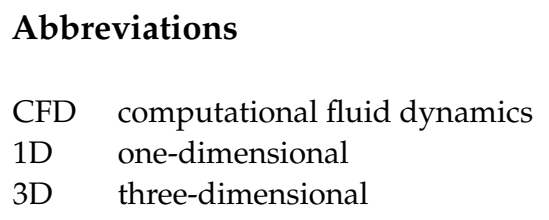

\section{Nomenclature}

$\begin{array}{lll}\text { Alphabets } & & \\ a & \text { half the length in the long axis direction of cross-sectional rectangle } & {[\mathrm{m}]} \\ b & \text { half the length in the short axis direction of cross-sectional rectangle } & {[\mathrm{m}]} \\ d & \text { flow path height } & {[\mathrm{m}]} \\ d_{\mathrm{H}} & \text { hydraulic diameter } & {[\mathrm{m}]} \\ d_{\mathrm{p}} & \text { particle size } & {[\mathrm{m}]} \\ f_{\mathrm{k}} & \text { the Fanning friction factor } & {[-]} \\ f_{\text {Darcy }} & \text { the Darcy friction factor } & {[-]} \\ F_{\mathrm{k}} & \text { fluid force } & {[\mathrm{N}]} \\ K & \text { constant defined by Equation (6) } & {[-]} \\ \mathbf{I} & \text { unit matrix } & {[-]} \\ L & \text { channel length from inlet to outlet } & {[\mathrm{m}]} \\ p & \text { pressure } & {[\mathrm{Pa}]} \\ \Delta p & \text { pressure drop } & {[\mathrm{Pa}]} \\ \text { Re } & \text { the Reynolds number } & {[-]} \\ S_{\mathrm{k}} & \text { surface area between the fluid and inner wall } & {\left[\mathrm{m}{ }^{2}\right]} \\ S_{\mathrm{p}} & \text { channel's cross-sectional area } & {\left[\mathrm{m}^{2}\right]} \\ u & \text { average flow velocity } & {\left[\mathrm{m} \cdot \mathrm{s}^{-1}\right]} \\ \mathbf{u} & \text { vector of flow velocity } & {\left[\mathrm{m} \cdot \mathrm{s}^{-1}\right]} \\ x & \text { coordinate along long side direction of channel's cross-section } & {[\mathrm{m}]} \\ y & \text { coordinate along short side direction of channel's cross-section } & {[\mathrm{m}]} \\ z & \text { coordinate along flow direction in channel } & {[\mathrm{m}]} \\ \text { Greek letters } & & \\ \rho & \text { density of fluid } & {\left[\mathrm{kg} \cdot \mathrm{m}{ }^{-3}\right]} \\ \tau_{\mathrm{w}} & \text { shear stress subjected to channel wall } & {[\mathrm{Pa}]} \\ \mu & \text { viscosity of fluid } & {[\mathrm{Pa} \cdot \mathrm{s}]} \\ \varepsilon & \text { absolute roughness } & {[\mathrm{m}]}\end{array}$

\section{References}

1. Mason, B.P.; Price, K.E.; Steinbacher, J.L.; Bogdan, A.R.; McQuade, D.T. Greener Approaches to Organic Synthesis Using Microreactor Technology. Chem. Rev. 2007, 107, 2300-2318. [CrossRef]

2. Hessel, V.; Kralisch, D.; Kockmann, N.; Noël, T.; Wang, Q. Novel Process Windows for Enabling, Accelerating, and Uplifting Flow Chemistry. ChemSusChem 2013, 6, 746-789. [CrossRef] [PubMed]

3. Rahimi, M.; Aghel, B.; Alitabar, M.; Sepahvand, A.; Ghasempour, H.R. Optimization of biodiesel production from soybean oil in a microreactor. Energy Convers. Manag. 2014, 79, 599-605. [CrossRef]

4. Murakami, S.; Ohtaki, K.; Matsumoto, S.; Inoue, T. Parallelization of Catalytic Packed-Bed Microchannels with Pressure-Drop Microstructures for Gas-Liquid Multiphase Reactions. Jpn. J. Appl. Phys. 2012, 51, 06FK11. [CrossRef]

5. Mei, D.; Lou, X.; Qian, M.; Yao, Z.; Liang, L.; Chen, Z. Effect of tip clearance on the heat transfer and pressure drop performance in the micro-reactor with micro-pin-fin arrays at low Reynolds number. Int. J. Heat Mass Transfer 2015, 70, 709-718. [CrossRef]

6. Tourvieille, J.N.; Philippe, R.; de Bellefon, C. Milli-channel with metal foams under an applied gas-liquid periodic flow: External mass transfer performance and pressure drop. Chem. Eng. J. 2015, 267, 332-346. [CrossRef]

7. Tsubogo, T.; Oyamada, H.; Kobayashi, S. Multistep continuous-flow synthesis of (R)- and (S)-rolipram using heterogeneous catalysts. Nature 2015, 520, 329-332. [CrossRef] [PubMed]

8. Adamo, A.; Beingessner, R.L.; Behnam, M.; Chen, J.; Jamison, T.F.; Jensen, K.F.; Monbaliuallan, J.-C.M.; Myerson, A.S.; Revalor, E.M.; Snead, D.R.; et al. On-demand continuous-flow production of pharmaceuticals in a compact, reconfigurable system. Science 2016, 352, 61-67. [CrossRef] [PubMed]

9. Jensen, K.F. Flow chemistry-Microreaction technology comes of age. AIChE J. 2017, 63, 858-869. [CrossRef]

10. Hasebe, S. Design and operation of micro-chemical plants-Bridging the gap between nano, micro and macro technologies. Comput. Chem. Eng. 2004, 29, 57-64. [CrossRef] 
11. Schenk, R.; Hessel, V.; Hofmann, C.; Kiss, J.; Löwe, H.; Ziogas, A. Numbering-up of micro devices: A first liquid-flow splitting unit. Chem. Eng. J. 2004, 101, 421-429. [CrossRef]

12. Saber, M.; Commenge, J.M.; Falk, L. Microreactor numbering-up in multi-scale networks for industrial-scale applications: Impact of flow maldistribution on the reactor performances. Chem. Eng. Sci. 2010, 65, 372-379. [CrossRef]

13. Engelbrecht, N.; Everson, C.R.; Bessarabov, D.; Kolb, G. Microchannel reactor heat-exchangers: A review of design strategies for the effective thermal coupling of gas phase reactions. Chem. Eng. Process._Process Intensif. 2020, 157, 108164. [CrossRef]

14. Görke, O.; Pfeifer, P.; Schubert, K. Highly selective methanation by the use of a microchannel reactor. Catal. Today 2005, 110, 132-139. [CrossRef]

15. Lerou, J.J.; Tonkovich, A.L.; Silva, L.; Perry, S.; McDaniel, J. Microchannel reactor architecture enables greener processes. Chem. Eng. Sci. 2010, 65, 380-385. [CrossRef]

16. Fukuda, T.; Kawanami, H.; Miyazawa, A. Development of a Newly Catalytic Plate-type Reactor and Its Evaluation of Methane Conversion and Pressure Drop in Dry Reforming of Methane. J. Chem. Eng. Jpn. 2017, 50, 657-665. [CrossRef]

17. Fukuda, T.; Harada, M.R.; Hamzah, A.B.; Ookawara, S.; Yoshikawa, S.; Matsumoto, H. Double-layered catalytic wall-plate microreactor for process intensification of dry reforming of methane: Reaction activity improvement and coking suppression. Chem. Eng. Process.-Process Intensif. 2021, 164, 108406. [CrossRef]

18. Hamzah, A.B.; Fukuda, T.; Ookawara, S.; Yoshikawa, S.; Matsumoto, H. Process intensification of dry reforming of methane by structured catalytic wall-plate microreactor. Chem. Eng. J. 2021, 412, 128636. [CrossRef]

19. Fukuda, T.; Maki, T.; Mae, K. Design of a Plate-Type Catalytic Microreactor with $\mathrm{CO}_{2}$ Permeation Membrane for Water-Gas Shift Reaction. Chem. Eng. Technol. 2012, 35, 1205-1213. [CrossRef]

20. Tullius, J.F.; Tullius, T.K.; Bayazitoglu, Y. Optimization of short micro pin fins in minichannels. Int. J. Heat Mass Transfer 2012, 55, 3921-3932. [CrossRef]

21. Yao, X.; Zhang, Y.; Du, L.; Liu, J.; Yao, J. Review of the applications of microreactors. Renew. Sustain. Energy Rev. 2015, 47, 519-539. [CrossRef]

22. Fukuda, T.; Sawada, M.; Maki, T.; Mae, K. Basic Design Concept of a Microreactor for Isothermal Operation Including Heat Conductivity. Chem. Eng. Technol. 2013, 36, 968-974. [CrossRef]

23. Fukuda, T.; Harada, R.M.; Miyazawa, A. Influence of channel dimensions and operational parameters on methane dry-reforming reaction in a catalytic wall-plate reactor and its design methodology. React. Chem. Eng. 2019, 4, 537-549. [CrossRef]

24. Peiyi, W.; Little, W.A. Measurement of friction factors for the flow of gases in very fine channels used for microminiature Joule-Thomson refrigerators. Cryogenics 1983, 23, 273-277. [CrossRef]

25. Pfahler, J.; Harley, J.; Bau, H.; Zemel, J. Liquid transport in micron and submicron channels. Sens. Actuators A Phys. 1990, 22, 431-434. [CrossRef]

26. Peng, X.F.; Peterson, G.P.; Wang, B.X. Frictional flow characteristics of water flowing through rectangular microchannels. Exp. Heat Transfer 1994, 7, 249-264. [CrossRef]

27. Wilding, P.; Shoffner, M.A.; Kircka, L.J. PCR in a silicon microstructure. Clin. Chem. 1994, 40, 1815-1818. [CrossRef]

28. Jiang, X.N.; Zhou, J.Y.; Yao, Y.L.; Ye, X.Y. Micro-fluid Flow In Microchannel. Proc. Transducers. 1995, 95, 317-320. [CrossRef]

29. Hetsroni, G.; Mosyak, A.; Pogrebnyak, E.; Yarin, L.P. Fluid Flow in Micro-Channels. Int. J. Heat Mass Transfer 2005, 48, 1982-1998. [CrossRef]

30. Kohl, M.J.; Abdel-Khalik, S.I.; Jeter, S.M.; Sadowski, D.L. An experimental investigation of microchannel flow with internal pressure measurements. Int. J. Heat Mass Transfer 2005, 48, 1518-1533. [CrossRef]

31. Nagamoto, H.; Kobayashi, Y.; Otomo, J.; Oshima, E. Laminar Flow Characteristics in a Rectangular Microchannel. Kagaku kogaku Ronbunshu 2006, 32, 293-296. (In Japanese) [CrossRef]

32. Pashchenko, D. Effect of the geometric dimensionality of computational domain on the results of CFD-modeling of steam methane reforming. Int. J. Hydrogen Energy 2018, 43, 8662-8673. [CrossRef]

33. Müller, W. Einführung in Die Theorie der Zähen Flüssigkeiten; (Nenseiryuutai no Rikigaku) (Translation); Korona-Sha: Tokyo, Japan, 1942; 82p.

34. Fukuda, T.; Harada, M.R.; Miyazawa, A. Heat exchangeability of a catalytic plate reactor and analysis of the reactivity of steam and $\mathrm{CO}_{2}$ in methane reforming. Chem. Eng. Technol. 2019, 42, 2127-2137. [CrossRef]

35. Moody, L.F. Friction factors for pipe flow. Trans. ASME 1944, 66, 671-684.

36. Harley, J.; Huang, Y.; Bau, H.; Zemel, J. Gas flow in micro-channels. J. Fluid Mech. 1995, 284, 257-274. [CrossRef] 